\title{
Effect of Feeding Different Cultivars of Leucaena leucocephala on Rumen-Based in vitro Anaerobic Fermentations ${ }^{\dagger}$
}

\author{
Diane Ouwerkerk 1,2,* , Anita Maguire 1, Jenny Gravel ${ }^{1}$, Cathy Minchin 1, Michael Gravel ${ }^{3}$, \\ Athol Klieve ${ }^{2}$ and Ros Gilbert ${ }^{1,2}$ \\ 1 Agri-Science Queensland, Department of Agriculture and Fisheries, Dutton Park, Brisbane 4102, Australia; \\ Anita.Maguire@daf.qld.gov.au (A.M.); Jenny.Gravel@daf.qld.gov.au (J.G.); \\ Catherine.Minchin@daf.qld.gov.au (C.M.); Ros.Gilbert@daf.qld.gov.au (R.G.) \\ 2 Queensland Alliance for Agriculture and Food Innovation, The University of Queensland, St Lucia, \\ Brisbane 4067, Australia; a.klieve@uq.edu.au \\ 3 Animal Biosecurity \& Welfare, Department of Agriculture and Fisheries, Coopers Plains, \\ Brisbane 4108, Australia; Michael.Gravel@daf.qld.gov.au \\ * Correspondence: Diane.Ouwerkerk@daf.qld.gov.au \\ + Presented at the third International Tropical Agriculture Conference (TROPAG 2019), Brisbane, Australia, \\ 11-13 November 2019.
}

Published: 13 February 2020

\begin{abstract}
The leguminous forage shrub, Leucaena leucocephala, is one of the few nutritional options available to significantly improve beef productivity in Northern Australia. A mixed bacterial rumen inoculum for the detoxification of mimosine (present in Leucaena) and its toxic derivatives 3,4 DHP and 2,3 DHP has been produced in an anaerobic fermenter for the last 23 years by the Queensland Department of Agriculture and Fisheries, using the commercial cultivar Cunninghamii. The development and release of a new psyllid-resistant cultivar 'Redlands', offers potential for increasing uptake by the beef industry but brings unanswered questions about its impact on the survival of the toxin degrading bacteria Synergistes jonesii and the overall efficacy of the current inoculum. A series of 30-day anaerobic fermentations were undertaken using the same starter cultures used in the production of commercial inoculum but fed daily with one of three Leucaena cultivars: Cunninghamii, Redlands or Wondergraze. Populations of S. jonesii were monitored daily using a quantitative PCR assay and the ability of the fermentation to detoxify mimosine and its derivatives were assayed on days 10, 15, 20, 25 and 30. Feeding the new Redlands cultivar had a negative impact on $S$. jonesii numbers and the ability to detoxify 3,4 DHP. However, as fermentation time increased, the $S$. jonesii populations adapted to the Redlands cultivar. A follow-on fermentation using a starter culture obtained from Day 30 of a Redlands fermentation, showed an immediate increase in S. jonesii populations and was able to detoxify mimosine and its toxic derivatives.
\end{abstract}

Keywords: Leucaena; Leucaena leucocephala; cattle; toxin; Synergistes jonesii; Redlands; mimosine; 3,4 DHP; 2,3 DHP; inoculum 
Author Contributions: Methodology, D.O., A.K.; data analysis, D.O, R.G., A.M., J.G., C.M., M.G.; Writing original draft preparation, D.O.; writing - review and editing, D.O., R.G., A.K., A.M., J.G., C.M., M.G.; project administration, D.O.; funding acquisition, D.O., A.K. All authors have read and agreed to the published version of the manuscript.

Funding: This research was funded by Meat \& Livestock Australia, grant number B.GBP.0026.

Acknowledgments: The authors would like to acknowledge DAF staff Craig Lemin, Joe Rolfe and Bernie English for supplying leucaena leaf material and Kerri Chandra for advice on statistical analysis.

Conflicts of Interest: The authors declare no conflict of interest.

(C) 2020 by the authors. Licensee MDPI, Basel, Switzerland. This article is an open access article distributed under the terms and conditions of the Creative Commons Attribution (CC BY) license (http://creativecommons.org/licenses/by/4.0/). 